\title{
Tailoring the Adsorption of ACE-inhibiting Peptides by Nitrogen Functionalization of Porous Carbons
}

Christiane Huettner ${ }^{a}$, Diana Hagemann ${ }^{b}$,Erik Troschke ${ }^{a}$, Felix Hippaufc, Lars Borchardt ${ }^{d}$, Steffen Oswalde, Thomas Henle ${ }^{b}$, Stefan Kaskela*

a Department of Inorganic Chemistry I, Technische Universität Dresden, Bergstraße 66, 01069 Dresden, Germany.

${ }^{\mathrm{b}}$ Department of Food Chemistry, Technische Universität Dresden, Bergstraße 66, 01069 Dresden, Germany.

c Fraunhofer Institute for Material and Beam Technology (IWS), Winterbergstraße 28, 01277 Dresden, Germany.

d Inorganic Chemistry, Ruhr Universität Bochum, Universitätsstraße 150, 44801 Bochum, Germany.

${ }^{\mathrm{e}}$ Leibniz Institute for Solid State and Materials Research Dresden (IFW), Helmholtzstraße 20, 01069 Dresden, Germany. 


\section{AUTHOR INFORMATION}

*Stefan Kaskel, Department of Inorganic Chemistry I, Technische Universität Dresden, Bergstraße 66, 01069 Dresden, Germany.

E-mail: Stefan.Kaskel@tu-dresden.de

Fax: +49 $351463-37287$

TABLE OF CONTENTS

\section{Material Synthesis S1}

Synthesis of N-doped materials

Table S1: Parameters for the functionalization of ROX 0.8 with melamine.

Figure S1: Temperature treatment for the synthesis of the covalent triazine framework.

\section{Nitrogen Physisorption Data $\quad$ S2-S4}

Figure S2: Nitrogen physisorption isotherms at $77 \mathrm{~K}$ for investigations of the influence of the pyrolysis temperature.

Figure S3: Nitrogen physisorption isotherms at $77 \mathrm{~K}$ for investigations of the influence of the duration of pyrolysis at different temperatures. 
Figure S4: Nitrogen physisorption isotherms at $77 \mathrm{~K}$ for investigations of the influence of the melamine content.

\section{Further Characterization Methods S2-S6}

Figure S5: N1s XPS spectra of ROX N and CTF.

Table S2: Content of different N species determined from XPS analysis.

Figure S6: SEM-images of ROX, ROX N and CTF. 


\section{SYNTHESIS OF N-DOPED MATERIALS}

For optimization of the functionalization of the activated carbon ROX 0.8 different parameters for the synthesis were varied. Three different molar ratios and pyrolysis temperatures and two different reaction times, shown in table S1, were carried out to investigate the influence on porosity and elemental composition and therefore hydrophobicity.

Table S1: Parameters for the functionalization of ROX 0.8 with melamine.

\begin{tabular}{|l|l|l|}
\hline $\begin{array}{l}\text { molar ratio } \\
\text { ROX 0.8:melamine }\end{array}$ & temperature $[\mathrm{K}]$ & duration $[\mathrm{h}]$ \\
\hline $1: 1$ & 873 & 2 \\
\hline & 873 & 3 \\
\hline & 973 & 2 \\
\hline & 973 & 3 \\
\hline & 1073 & 2 \\
\hline $1: 2$ & 873 & 3 \\
\hline & 973 & 3 \\
\hline $10: 1$ & 873 & 3 \\
\hline
\end{tabular}

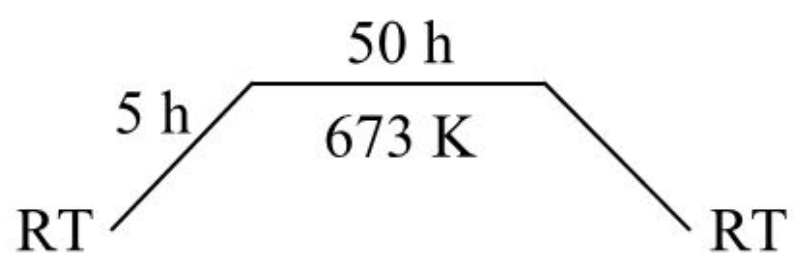

Figure S1: Temperature treatment for the synthesis of the covalent triazine framework. 


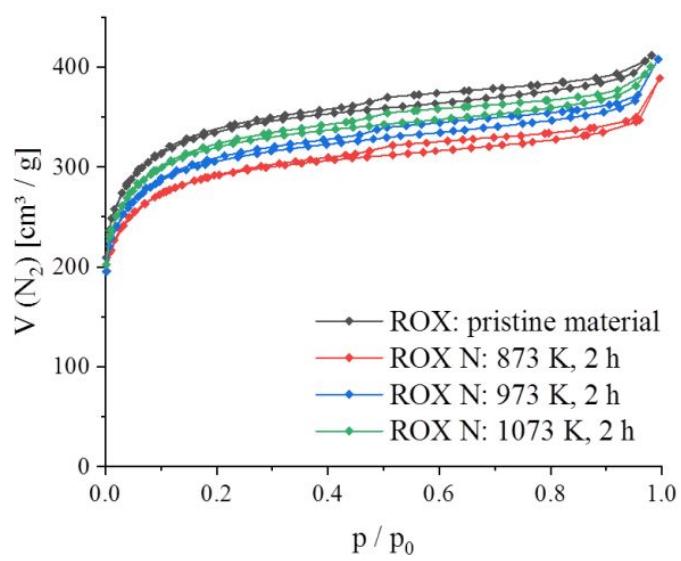

Figure S2: Nitrogen physisorption isotherms at $77 \mathrm{~K}$ for investigations of the influence of the pyrolysis temperature.

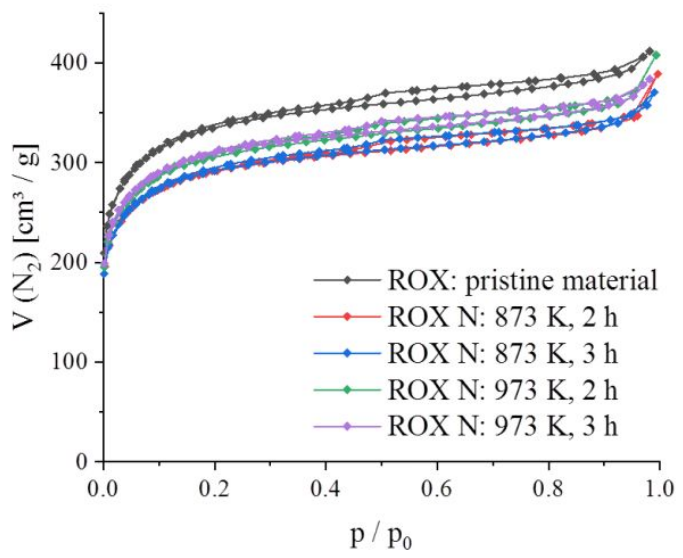

Figure S3: Nitrogen physisorption isotherms at $77 \mathrm{~K}$ for investigations of the influence of the duration of pyrolysis at different temperatures. 


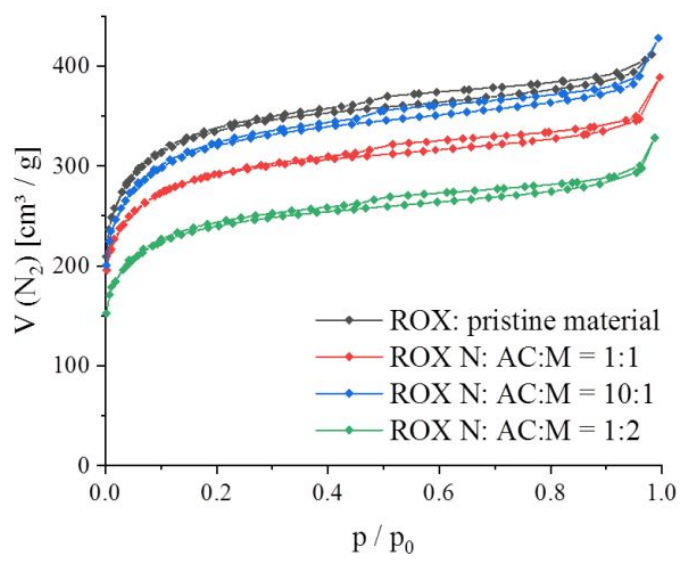

Figure S4: Nitrogen physisorption isotherms at $77 \mathrm{~K}$ for investigations of the influence of the melamine content. 
a)

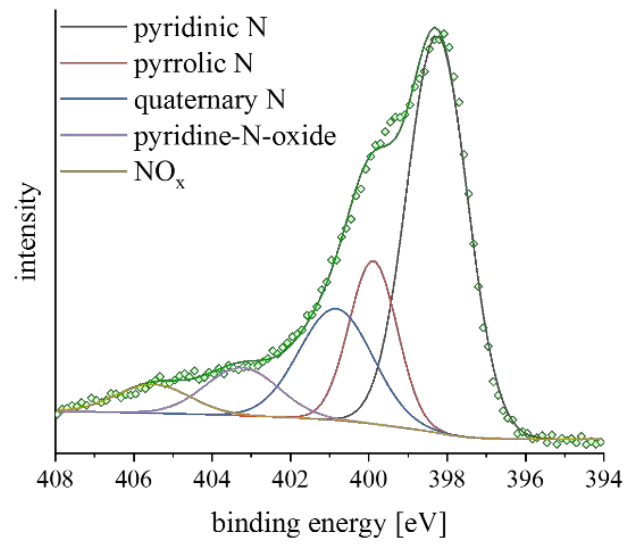

b)

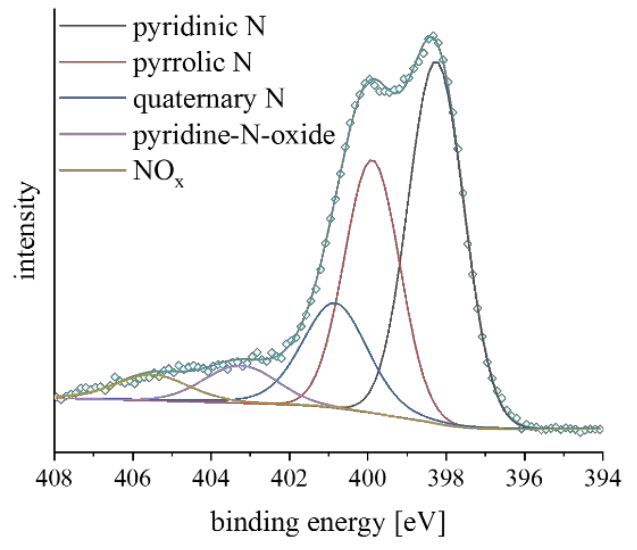

Figure S5: N1s XPS spectra of (a) ROX N (green), (b) CTF (cyan). Symbols represent the data, lines the fit.

Table S2: Content of different N species determined from XPS analysis.

\begin{tabular}{|l|l|l|l|l|l|}
\hline & $\begin{array}{c}\text { Pyridinic N } \\
{[\%]}\end{array}$ & $\begin{array}{c}\text { Pyrrolic N } \\
{[\%]}\end{array}$ & $\begin{array}{c}\text { Quaternary N } \\
{[\%]}\end{array}$ & $\begin{array}{c}\text { Pyridine-N- } \\
\text { oxide [\%] }\end{array}$ & \multicolumn{1}{|c|}{$\mathbf{O}_{\mathbf{x}}$ [\%] } \\
\hline ROX N & 52.54 & 17.09 & 17.81 & 7.73 & 4.83 \\
\hline CTF & 41.6 & 35.32 & 12.98 & 5.68 & 4.41 \\
\hline
\end{tabular}



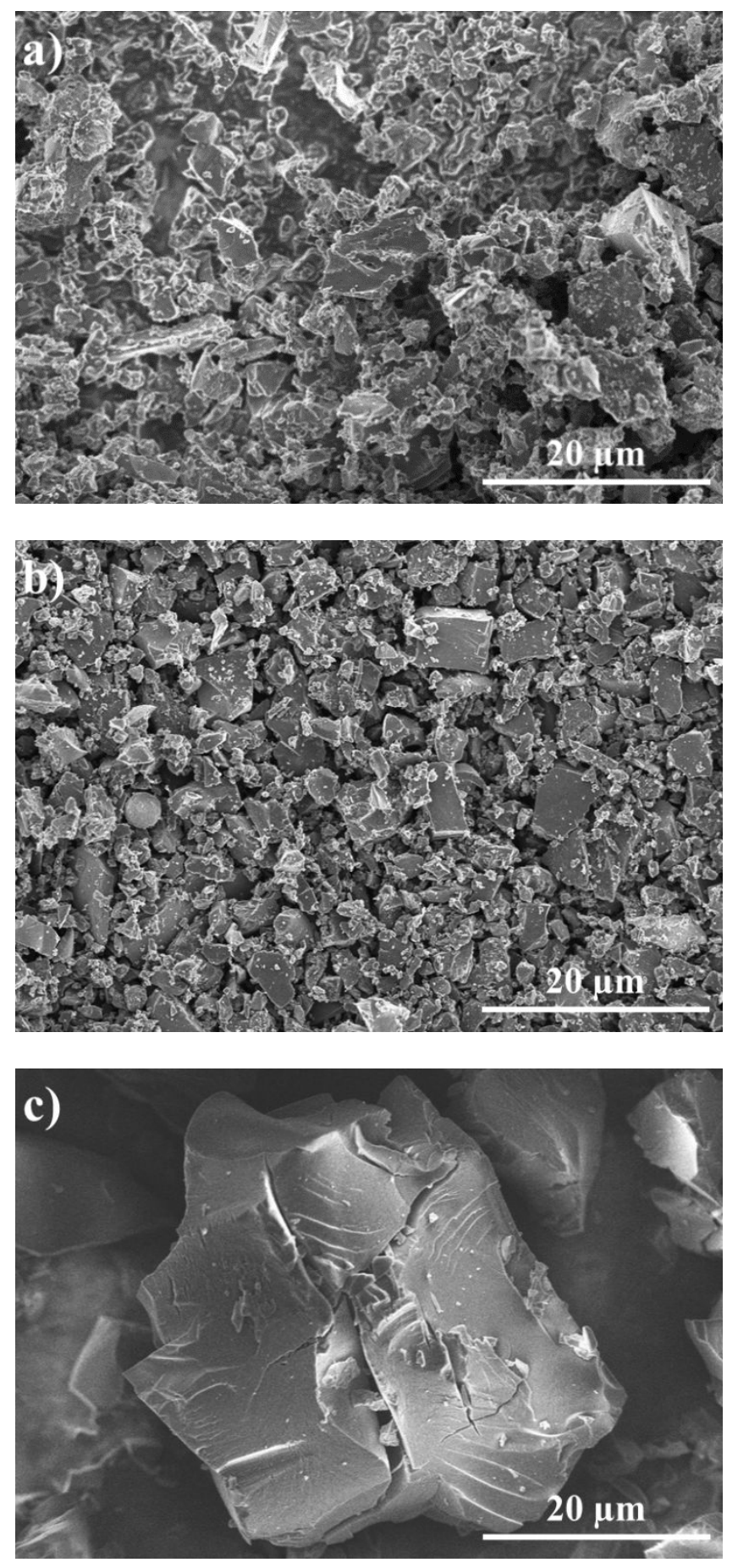

Figure S6: SEM-images of (a) ROX, (b) ROX N, (c) CTF. 